\title{
HTR-10GT Dual Bypass Valve Control Features and Decoupling Strategy for Power Regulation
}

\author{
Xiao Li, Xiaoyong Yang, Youjie Zhang, and Jie Wang \\ Institute of Nuclear and New Energy Technology of Tsinghua University, Collaborative Innovation Center of \\ Advanced Nuclear Energy Technology, The Key Laboratory of Advanced Reactor Engineering and Safety, Ministry of Education, \\ Beijing 100084, China \\ Correspondence should be addressed to Youjie Zhang; zhangyj@tsinghua.edu.cn
}

Received 9 October 2016; Accepted 10 January 2017; Published 13 February 2017

Academic Editor: Eugenijus Ušpuras

Copyright (C) 2017 Xiao Li et al. This is an open access article distributed under the Creative Commons Attribution License, which permits unrestricted use, distribution, and reproduction in any medium, provided the original work is properly cited.

\begin{abstract}
HTR-10GT is the development of HTR-10 reactor, which PCU will be a closed Brayton cycle with two-stage compression and heat recuperation. Bypass control method is adopted for rapid power regulation and safety protection. But quick opening of single bypass valve would inevitably lead to temperature shocks in multiple components especially at the reactor inlet and the recuperator core. Based on the regulating characteristics of each possible bypass valve, a dual bypass valve control scheme was proposed along with MIMO decoupling controller designed with diagonal matrix method. The system was modeled with Modelica; the DASSL code was used to solve the Differential and Algebraic Equations during simulations. System's control characteristic was analyzed with classical linear control theory and $H_{\infty}$ theory applied on linearized system model. Further numerical simulations showed that cooperative functioning of two bypass valves could effectively limit the temperature variation during power regulation, while the decoupler could improve the control effect and the stability of the system. The results will be helpful for the future design of the control system of HTR-10GT or other closed Brayton cycle of the same kind.
\end{abstract}

\section{Introduction}

Closed Brayton cycle coupled with high temperature gascooled reactor (HTGR) has potential application due to its compact configuration, high efficiency, and inherent safety. Furthermore, it is one of the major power conversion methods for Generation IV advanced nuclear power systems [1]. Researchers from all over the world proposed designs based on this principle; however, the configuration of closed Brayton cycle varies from direct cycles to indirect cycles, from pure power production system to cogeneration system.

Three power regulation methods were generally adopted in such closed Brayton cycle: reactivity control for reactor outlet temperature adjustment, inventory control for slow power regulation maintaining high cycle efficiency, and bypass valves control for rapid power regulation. In almost all existing designs of reactor coupled closed Brayton cycles, such as MPBR, MGR-GT, GTHTR-300C, GT-MHR, ACACIA, and PBMR, bypass valve was set but with different strategies [2-7]. MPBR and GT-MHR applied single bypass valve for system simplicity: the bypass valve from MPBR design diverts the helium flow from the heat source and the turbines [2] and that from GT-MHR design bypasses the reactor, the turbine, and the high-pressure side of the recuperator [3]. The bypass valve for shaft speed control on GTHTR-300C was set from the compressor outlet to the precooler inlet controlled by single loop PI feedback control [4]. Some other designs introduced two or more bypass valves for rapid power regulation, meanwhile relieving the thermal shock brought by instant opening of large single bypass valve. In the design of MGR-GT, two bypass valves were applied, one for shaft speed control leading from the recuperator high-pressure side outlet to the turbine outlet and the other one for turbine outlet temperature control leading from the compressor outlet to the turbine outlet. Yan [5] designed a plant regulation system which applied separated PID control loops. The potential coupling phenomenon between the loops was neglected, as only $10 \%$ step load variation was analyzed in his research. Besides these 2 positions, Kikstra and Verkooijen [6] proposed 2 another alternative positions: from the compressor outlet to its inlet and to the recuperator low-pressure 
side outlet. Based on the control features obtained, Relative Gain Array method and Dynamic Relative Gain analysis were applied for input-output pairing and the interaction between different control loops were paid attention; however, no countermeasure was mentioned in his research. In the PBMR design, valves of different functions were set at 5 positions including a low-pressure compressor bypass valve as an auxiliary method for shaft speed control and a recuperator bypass valve to adjust heat regenerated [7].

Due to engineering's constraints of HTR-10, the effectiveness of recuperator is quite low in HTR-10GT, and the system behavior of such design needs further investigation. Only the effects of one bypass valve in HTR-10GT were discussed in previous papers [9]. The other possible positions of single bypass valve and dual bypass valves' control were not being studied. In this paper, all possible single bypass valve positions and the possible dual valve pairs were discussed. The system's features were analyzed with numerical simulation on system models coded with Modelica to determine an optimal combination of valves for rapid power regulation and temperature stabilization. Also a decoupling controller structure was designed with diagonal matrix method [10] to reduce the interaction between the two valves. The improvements on the control effect and the robustness were shown by simulations and multiloop disk margin analysis.

\section{System Modeling}

2.1. HTR-10GT Structure. The purpose of the HTR-10GT project is to couple the $10 \mathrm{MW}$ high temperature gas-cooled reactor test module (HTR-10) with a direct helium gas turbine cycle. A power conversion unit of gas turbine cycle, which will be installed instead of the HTR-10 steam generator in the vertical pressure vessel, is designed to convert fission energy generated in the reactor core into electric energy. Figure 1 shows the schematic layout of HTR-10GT, which is a single shaft intercooled recuperated closed Brayton cycle combined with HTGR. It contains 8 major processes in 7 components: the reactor (REA), low-/high-pressure compressor (LPC/HPC), turbine (TUR), recuperator (RC), precooler (PC), and intercooler (IC). The conventional power regulation methods for closed Brayton cycle are also illustrated in the figure: the reactor outlet temperature control (ROT), the inventory control (INV), and bypass valve control (BPV). 6 candidates bypass valves are numbered with letters $\mathrm{A} \sim \mathrm{F}$ for later discussion. The INV and BPV control systems are set outside the PCU pressure vessel with pipes penetrating the PCU pressure vessel.

Numbers 1 6 in Figure 1 are used to characterize gas states at different positions in the thermodynamics cycle as subscript. $2 \mathrm{a}$ and $2 \mathrm{~b}$ are added to express the extra positions brought by intercooling. $5 \mathrm{a} / 5 \mathrm{~b}$ and $6 \mathrm{a} / 6 \mathrm{~b}$ are used to distinguish the states between before and after the flow mixing from the bypass route.

Helium heated in the HTR-10 reactor core goes along the hot gas duct into the turbine. The shaft power obtained from expansion of hot compressed helium in turbine drives the compressors and the generator for electricity output. Then, helium flows along the recuperator low-pressure side,

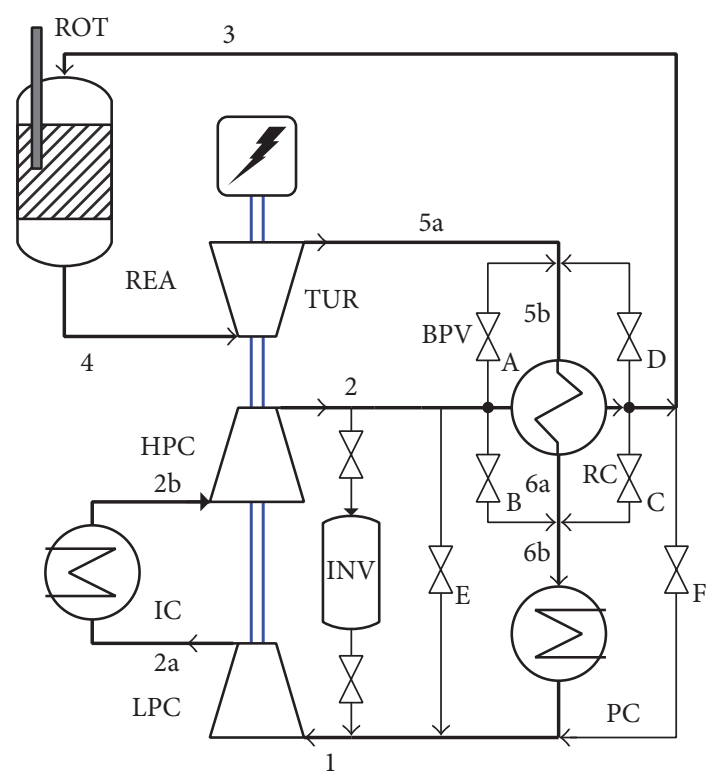

FIGURE 1: Layout of the system structure of HTR-10GT with candidate bypass valve positions illustrated.

TABLE 1: Specification of HTR-10GT [8].

\begin{tabular}{lc}
\hline Parameters & Value \\
\hline Reactor power $(\mathrm{MW})$ & 10 \\
Reactor inlet/outlet temperature $\left({ }^{\circ} \mathrm{C}\right)$ & $330 / 752$ \\
Reactor inlet/outlet pressure $(\mathrm{MPa})$ & $1.53 / 1.52$ \\
Reactor mass flowrate $(\mathrm{kg} / \mathrm{s})$ & 4.55 \\
Shaft speed $(\mathrm{r} / \mathrm{min})$ & 15000 \\
Turbine expansion ratio & 2.2 \\
Compressor ratio for HPC & 1.58 \\
Compressor ratio for LPC & 1.58 \\
Recuperator effectiveness & 0.575 \\
Helium temperature at precooler/intercooler outlet $\left({ }^{\circ} \mathrm{C}\right)$ & 35 \\
\hline
\end{tabular}

transferring exhaust heat to helium counterflowing along the high-pressure side of recuperator. Further, the helium was cooled by precooler and then compressed in LPC and HPC with intercooling. All the thermal-hydraulics and numerical simulation were based on the parameters of the HTR-10GT settings as case study. The key parameters of the system were listed in Table 1.

2.2. Component Models. The entire system was modeled with component-by-component method in multifield modeling language Modelica and was implemented uniformly into DAEs (Differential Algebraic Equations) in simulation environment OpenModelica [11]. The equations were solved with the DASSL code which is Backward Differentiation Formulas of orders 1 through 5 [12].

2.2.1. Fluid Networks and Heat Exchanger Models. As helium is the working fluid, all flow paths are modeled as single phase 1-dimensional flow dominated by mass, momentum, and energy conservations and discretized in control volume 
method; thus, the main dynamic characteristics such as thermal inertia, volume inertia, and hydraulic shock effect could be kept. Assuming that the flow channel has constant cross section area $A$ and length $L$, the conservation equations could be expressed in following form:

$$
\begin{aligned}
A \frac{\partial \rho}{\partial t}+\frac{\partial w}{\partial x} & =0, \\
\frac{\partial w}{\partial t}+A \frac{\partial p}{\partial x}+\frac{1}{\rho A} \frac{\partial w^{2}}{\partial x}+\frac{k_{f}}{\rho} w|w| & =0, \\
\rho A \frac{\partial h}{\partial t}+w \frac{\partial h}{\partial x}-A \frac{d p}{d t} & =\omega \varphi,
\end{aligned}
$$

where $\rho, w, p, h$ represent, respectively, fluid's density, mass flowrate, pressure, and specific enthalpy. Friction coefficient $k_{f}$ is defined as $k_{f}=f \cdot \omega \cdot L / 2 A^{3}, \varphi$ is heat flux, and $\omega$ is wetted perimeter. As temperature has slower response than mass flow and momentum, energy conservation equation is integrated along control volumes, while the other two conservation equations are integrated along the whole path.

$$
\begin{aligned}
& A l\left(\left.\sum_{1}^{\mathrm{N}} \frac{\partial \rho}{\partial h}\right|_{p} \frac{d \bar{h}_{j}}{d t}+\left.\sum_{1}^{\mathrm{N}} \frac{\partial \rho}{\partial p}\right|_{h} \frac{d p_{\text {out }}}{d \mathrm{t}}\right)=w_{\text {in }}-w_{\text {out }}, \\
& \frac{L}{A} \frac{d w_{\text {in }}}{d t}+\left(p_{\text {out }}-p_{\text {in }}\right)+\frac{k_{f} w_{\text {in }}\left|w_{\text {in }}\right| L}{\mathrm{~N}-1} \sum_{j=1}^{\mathrm{N}-1} \bar{v}_{j}=0, \\
& A \widetilde{\rho}_{j} l \frac{\partial \bar{h}_{j}}{\partial t}+w_{\text {in }}\left(h_{\text {out }, j}-h_{\text {in }, j}\right)-A l \frac{d p_{\text {out }}}{d t}=\omega l \bar{\varphi}_{j},
\end{aligned}
$$

where $l$ is the length of a single control volume and $\bar{h}_{j}, \widetilde{\rho}_{j}$, and $\bar{v}_{j}$ are mean specific enthalpy, density, and specific volume of the $j$ th control volume. In this $1 \mathrm{D}$ distributed parameter model, the longitudinal heat diffusion term is neglected, so is the velocity diffusion. Heat exchangers are modeled with two flow paths and the discretized metal wall between them, considering thermal inertia and thermal resistance. The heat transfer calculating formula was chosen based on practical condition like laminar/turbulent flow, flow through pebble bed, or transverse flow tube bundle.

2.2.2. Reactor Core Modeling. The neutron dynamics of the reactor core is simplified with 6 precursor groups of delayed neutron point-kinetics as shown in (3). The reactivity is calculated by (4), considering rod insertion, the reactivity feedback from temperature variation of the fuel, the moderator, and the reflector.

$$
\begin{aligned}
& \frac{d n}{d t}=\frac{\rho_{R}-\beta}{\Lambda} n+\sum_{i=1}^{6} \lambda_{i} c_{i}, \\
& \frac{d c_{i}}{d t}=\frac{\beta}{\Lambda} n-\lambda_{i} c_{i} \quad i=1, \ldots, 6,
\end{aligned}
$$

where $c$ is the precursor concentration leading to a delayed neutron source, $\rho_{R}$ is the total reactivity of the core defined as (4), $\beta$ is the fraction of the delayed neutrons, $\lambda$ is the decay constant of the precursors, and $\Lambda$ is the characteristic period of the mean neutron generation time.

$$
\rho_{R}=\rho_{R, \text { rod }}+\left(\alpha_{f}+\alpha_{m}\right)\left(T_{c}-T_{c 0}\right)+\alpha_{r}\left(T_{r}-T_{r 0}\right) .
$$

10-node 1D flow model mentioned above was used to model the flows through the fuel, riser, and downcomer nodalized into 10 control volumes, while lumped models were used for the reflector, lower header, upper header, and output header. A constant leakage proportion was set between the lower header and the output header.

2.2.3. Turbomachinery Models. As the internal volumes of compressors and turbines are relatively small, the volume inertia inside turbomachines is inconspicuous. Quasi-steadystate models are sufficient to reflect their characteristics. In this paper, compressor performance maps were used to estimate the status under off-design conditions defined with a group of thermodynamic variables: inlet corrected mass flowrate $w_{c}=w \sqrt{T} / p$, the pressure ratio of the compressor $\pi$, the isentropic efficiency of the compressor $\eta_{\text {is }}$, the design corrected rotational speed $N_{c}=N / \sqrt{T}$, and the surge-pressure ratio $\pi_{\text {surge }}$. The map was converted into a look-up table for computational efficiency. To avoid ambiguous digitization, the so-called beta lines were introduced to the compressor map forming the auxiliary coordinates with iso- $N_{c}$ lines. These beta lines are approximately parallel with the surge line and the choke line and are equally spaced between them. For identification purposes, the auxiliary coordinates are attributed equidistant values between 0 (choke) and 1 (surge).

As the establishment of the compressor performance map was based on self-modeling area hypothesis, which is not always satisfied in partial load conditions with minor Reynolds number, WASSELL method was introduced to correlate Reynolds number effects empirically with preexisting compressor data [13]. Compressor efficiency, pressure ratio, mass flow, and surge-pressure ratio which are influenced by Reynolds number effects are corrected with corresponding correlations.

For the turbine, which has 6 stages in HTR-10GT design, Flügel formula [14] is sufficient accurate for its performance estimation:

$$
\begin{aligned}
\frac{w}{w_{d}} & =\frac{p}{p_{d}} \sqrt{\frac{T_{d}}{T}} \sqrt{1-0.4 \frac{\Delta N}{N_{d}}} \sqrt{\frac{1-\pi^{-2}}{1-\pi_{d}^{-2}}}, \\
\frac{\eta_{\mathrm{TUR}}}{\eta_{\mathrm{TUR}, d}} & =\frac{N}{N_{d}} \sqrt{\frac{h_{\mathrm{is}, d}}{h_{\mathrm{is}}}}\left(2-\frac{N}{N_{d}} \sqrt{\frac{h_{\mathrm{is}, d}}{h_{\mathrm{is}}}}\right) .
\end{aligned}
$$

2.2.4. Valve Model. This model is based on the IEC 534/ISA S.75 standard for valve sizing for compressible fluid. The relationship between the mass flowrate and the pressure difference satisfies

$$
w=A_{V} Y \sqrt{\rho p_{1} x_{s}}
$$

where $A_{V}$ represents metric flow coefficient with the dimension $\left[\mathrm{m}^{2}\right], p_{1}$ is the absolute static pressure upstream, $x$ is 
ratio of pressure drop to absolute inlet pressure $\left(\Delta p / p_{1}\right)$, and $x_{s}$ is its saturated value defined by

$$
x_{s}= \begin{cases}x, & x<F_{k} x_{T} f(\theta), \\ F_{k} x_{T} f(\theta), & x \geq F_{k} x_{T} f(\theta),\end{cases}
$$

where $F_{k}$ and $x_{T}$ represent ratio of specific heats factor and pressure drop ratio factor, respectively. Due to sonic conditions in the vena contracta, the flow is choked for highpressure difference; $x_{s}$ is thus limited. The valve characteristic function $f(\theta)$ is assumed linear to valve opening $\theta$ in this study. The compressibility factor $Y$ is defined by

$$
Y=1-\frac{x_{s}}{3 F_{k} x_{T}}
$$

The dynamic of valves was modeled as first-order inertial elements with the gain of 1 and the characteristic time of 0.5 seconds.

\section{Decoupling Controller Design}

Systems with more than one input and/or more than one output are known as Multi-Input Multi-Output (MIMO) systems. As linearization theorem is a powerful tool in stability analysis of a nonlinear function near a given point, HTR10GT's integrate system model was linearized for control design analysis and was described with continuous timeinvariant form state-space equations:

$$
\begin{aligned}
& \dot{\mathbf{X}}(t)=\mathbf{A X}(t)+\mathbf{B} \mathbf{U}(t), \\
& \mathbf{Y}(t)=\mathbf{C X}(t)+\mathbf{D} \mathbf{U}(t) .
\end{aligned}
$$

As the system model has 135 states and there are 2 pairs of input $\mathbf{U}(t)$ and output $\mathbf{Y}(t)$, the sizes of the 4 matrices $\mathbf{A}, \mathbf{B}$, C, $\mathbf{D}$ are, respectively, $135 \times 135,135 \times 2,2 \times 135$, and $2 \times 2$.

3.1. MIMO System Coupling Analysis. The coupling degrees between different regulation methods could be measured through RGA (Relative Gain Array) methods [15]. The global RGA analysis showed that reactivity control and the temperature at the reactor outlet formed an optimal inputoutput pairing, and there is strong coupling between the rest of two methods and between different bypass valves. As the difference between the characteristic time of inventory control and bypass valve control is huge, the coupling effect turns out to be unapparent. Thus, decoupling controller was designed aiming against the coupling between different bypass valves during cooperative regulation. The RGA of the two bypass valves could be expressed as follows:

$$
\operatorname{RGA}(\mathbf{G})=\mathbf{G} *\left(\mathbf{G}^{-1}\right)^{T}
$$

where $\mathbf{G}$ is the steady-state gain matrix defined as $\mathbf{G}_{i j}=$ $\left(\partial y_{i} / \partial x_{j}\right)_{u_{k}, k \neq j}$ and $*$ denotes element-by-element multiplication (Schur product) between two matrices.
3.2. Diagonal Matrix Decoupling Method. In order to reduce the interaction between the two control loops, set point changes affect only the desired controlled variable; a decoupling controller should be introduced and designed with the linearized model. A general feedback 2-input 2-output decoupling control system presents in the structure shown in Figure 2.

In the diagram, each block could be in form of transfer function or state space for continuous linear system. The function of the decoupler is to cancel out the effect of $U_{2}$ on $Y_{1}$. For each channel, we want

$$
\begin{aligned}
& G_{p 11} D_{11}+G_{p 12} D_{21}=G_{p 11}, \\
& G_{p 22} D_{22}+G_{p 21} D_{12}=G_{p 22}, \\
& G_{p 11} D_{12}+G_{p 12} D_{22}=0, \\
& G_{p 22} D_{21}+G_{p 21} D_{11}=0 .
\end{aligned}
$$

As a result, the transfer function of the decoupler blocks could be determined:

$$
\begin{aligned}
& D_{11}=D_{22}=\frac{G_{p 11} G_{p 22}}{G_{p 11} G_{p 22}-G_{p 12} G_{p 21}}, \\
& D_{12}=-\frac{G_{p 12} D_{22}}{G_{p 11}}, \\
& D_{21}=-\frac{G_{p 21} D_{11}}{G_{p 22}} .
\end{aligned}
$$

3.3. Robustness Evaluation. Linearized system models always have uncertainty, from a wide range of sources: model errors, hydraulic actuator gain and phase changes from nonlinear limiting effects, uncertain time delays from operation, sensor calibration errors, and many others.

The loop gain matrix $\mathbf{L}$ is associated with the input or output loops broken simultaneously. Normally, classical gain and phase margins are used to evaluate the relative stability of a closed-loop system. The gain margin is the amount of gain increase or decrease required making the loop gain unity at the frequency where the phase angle is $-180^{\circ}$, and the phase margin is the difference between the phase of the response and $-180^{\circ}$ when the loop gain is 1.0. The classical gain and phase margins could be obtained through Bode plot or Nyquist plot.

In order to interpret singular value-based robustness measures in terms of multivariable gain and phase margins with symmetric gain margins expression, balanced sensitivity function $\mathbf{S}-\mathbf{T}$ was introduced [16] and expressed as

$$
\mathbf{S}-\mathbf{T}=(\mathbf{I}+\mathbf{L})^{-1}-\mathbf{L}(\mathbf{I}+\mathbf{L})^{-1}=(\mathbf{I}-\mathbf{L})(\mathbf{I}+\mathbf{L})^{-1}
$$

This expression can be motivated by considering the particular type of uncertainty on the plant output shown in Figure 2, where $\Delta$ represents the transfer matrix of the perturbation. Then, the transfer matrix "seen" by $\Delta$ is (I $\mathbf{L})(\mathbf{I}+\mathbf{L})^{-1}$. Similarly, the transfer matrix "seen" by $\mathbf{L}$ is 


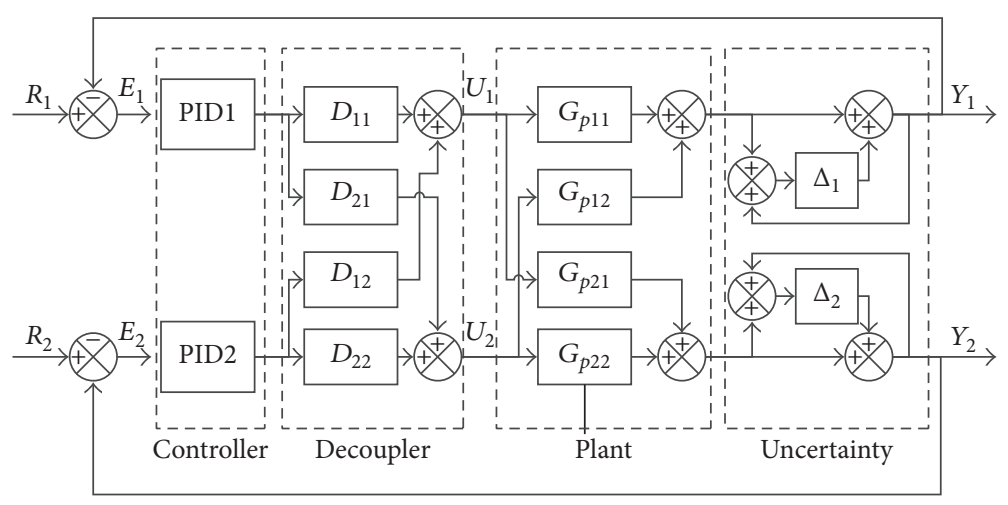

Figure 2: Control block diagram for decoupler design and robustness analysis.

$(\mathbf{I}-\Delta)(\mathbf{I}+\Delta)^{-1}$, where each $\Delta_{i}$ varies inside the complex disk $r e^{-j \theta}$ where $\theta \in[0,2 \pi]$.

From the Small Gain Theorem, the system would not lose stability if $\bar{\sigma}\left(\operatorname{diag}\left(\boldsymbol{\Delta}_{1}, \boldsymbol{\Delta}_{2}\right)\right) \bar{\sigma}\left((\mathbf{I}-\mathbf{L})(\mathbf{I}+\mathbf{L})^{-1}\right)<1$, where $\bar{\sigma}$ represents the maximum singular value. Since the uncertainty in each loop is of form $\left(1-r e^{-j \theta}\right) /\left(1+r e^{-j \theta}\right)$, the extreme gain changes occur at $\theta=0$ and $\pi$, and multiloop disk margin could be determined as follows:

$$
\begin{aligned}
\mathrm{DGM} & =\left[\frac{1-r_{\min }}{1+r_{\min }}, \frac{1+r_{\min }}{1-r_{\min }}\right], \\
\mathrm{DPM} & =\left[-2 \tan ^{-1}\left(r_{\min }\right), 2 \tan ^{-1}\left(r_{\text {min }}\right)\right],
\end{aligned}
$$

where DGM and DPM represent disk gain margin and disk phase margin, respectively, and $r_{\text {min }}$ is calculated with

$$
r_{\min }=\inf _{\omega \in \mathscr{R}} \frac{1}{\bar{\sigma}\left[(\mathbf{I}-\mathbf{L})(\mathbf{I}+\mathbf{L})^{-1}\right]} .
$$

Unlike disk margins that were determined channel by channel separately, multiloop disk margin were calculated based on full system including the controller, the decoupler, and the plant where interferences were put into consideration between the two feedback channels with the worst direction. It is a conservative robustness guarantee for all frequencies.

\section{Analysis Results and Discussions}

In this section, the selection process and comparison of single bypass valve positions are presented by the steadystate and dynamic behavior analysis results. Then analysis on coopening of bypass valve pairs is used to reflect the advantages of the dual bypass valve scheme. Finally, the improvements on the control effect and robustness brought by decoupling controller are proved by simulations and disk margin analysis.

4.1. System Responses to Single Bypass Valve. A bypass valve could be set between any two positions at different pressure levels. There are thus 21 possibilities. However, 15 of them should eliminated from the candidate list for safety and efficiency concerns. For the 12 positions where only one

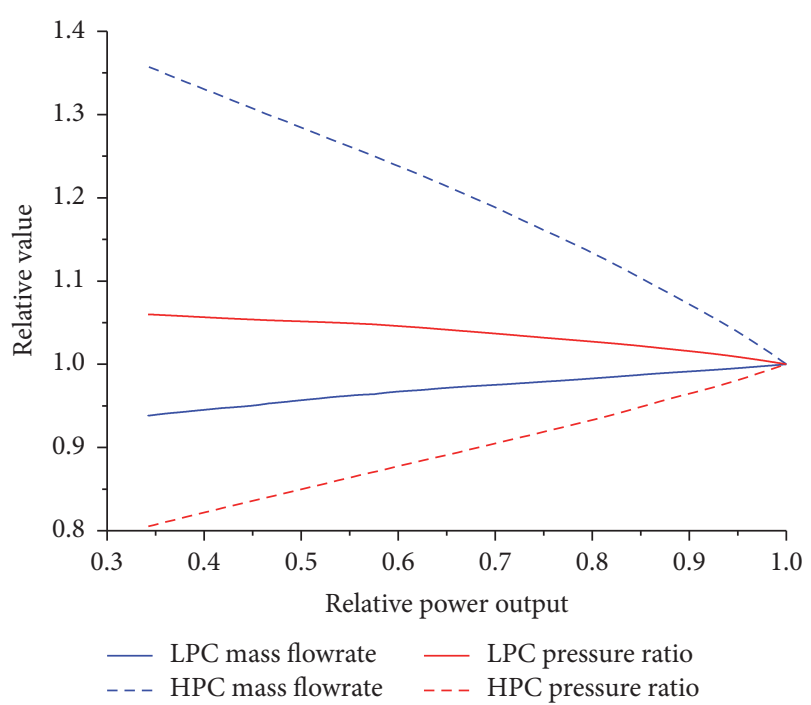

FIGURE 3: Pressure ratio and flowrate characteristics when bypassing HPC.

compressor is bypassed, the bypassed compressor would trend towards choke, while the performance of the other one would deteriorate seriously, which would boost the risk of instability of the entire turbosystem. Taking bypassing HPC from 2 to 2a (illustrated in Figure 1) as example, the mass flowrate and pressure ratio characteristics are shown in Figure 3: the HPC and LPC have diverse variation trends, and the power output could not be reduced to less than $35 \%$ of the rated value as the bypass compressor is already choked.

The trends are clearer when illustrated on compressor performance map as shown in Figure 4. While the operating point of bypassed compressor touches the choke line, the performance of the unbypassed compressor would approach the surge line. Based on the calculation, the surge margin defined as $\mathrm{SM}=100 \% \cdot\left(w-w_{\text {surge }}\right) / w_{\text {surge }}$ decreases to $3.35 \%$ taking account of the shift of the surge line caused by Reynolds number effect. During the operation of a compressor system, the surge margin under $15 \%$ is unacceptable.

Within the remaining 9 possibilities, the bypass paths beginning at the outlet of reactor core should be avoided for the reason that such bypass paths would increase the flowrate 


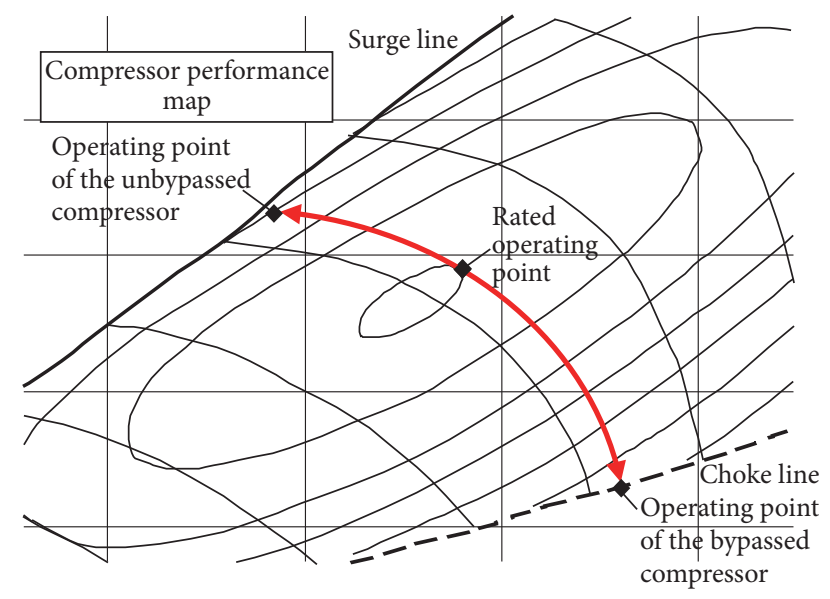

FIGURE 4: Working points variation on performance map when bypassing single compressor.

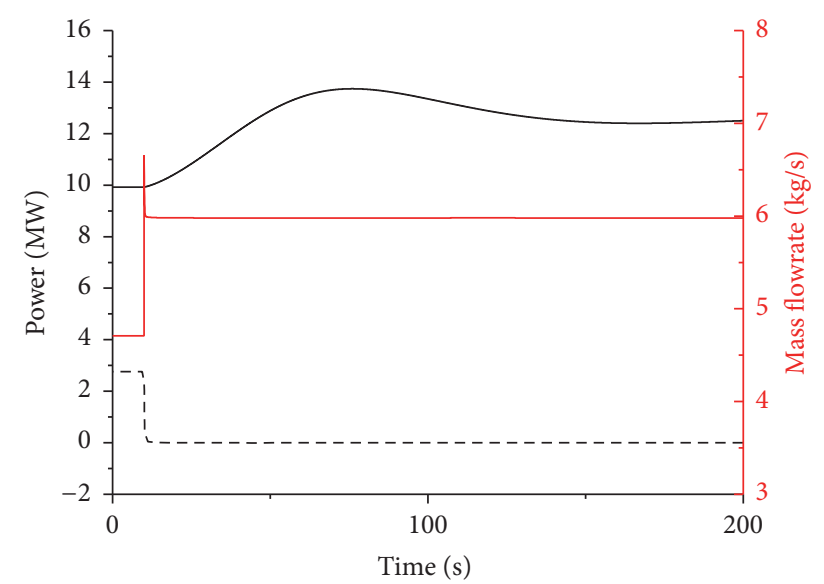

- Reactor power $\quad$ Mass flowrate through reactor
- Output power

FIGURE 5: Mass flowrate and power responses of reactor when bypassing the turbine alone.

through the reactor which has a positive impact on the neutron economy and reactor power. The result in Figure 5 shows that the rise of the mass flowrate through the reactor core would cause reactor power increasing to a peak value of $14 \mathrm{MW}$ for its negative temperature coefficient. Instantaneously promoting the reactor thermal power while reducing the load violates the purpose of the bypass valve regulation.

Engineering constraints, such as strength of pressure vessel affected by temperature and opening, must be taken into consideration in analysis to prevent leakage of radioactivity. Low alloy ferritic and bainitic steel, SA533 Grade B Class 1 plate and SA508 Grade 3 Class 1 forgings (508/533), are adopted to manufacture the pressure vessel of reactor and PCU. Normal operating temperatures of SA 508/533 cannot exceed the $350^{\circ} \mathrm{C}$ by ASME Code Sections III. Opening on pressure vessel will cause three kind of stresses, including membrane stress, bending stress, and peak stress. These stresses will reduce the strength of pressure vessel, especially at relative high operating temperature. So the numbers
TABLE 2: Long-term features opening single bypass valve to 0 power output.

\begin{tabular}{lcccccc}
\hline Conditions & $\begin{array}{c}A_{v} \\
\text { required } \\
\left(\mathrm{m}^{2}\right)\end{array}$ & $\begin{array}{c}T_{3} \\
(\mathrm{~K})\end{array}$ & $\begin{array}{c}T_{5 \mathrm{~b}} \\
(\mathrm{~K})\end{array}$ & $\pi$ & $\begin{array}{c}w_{\mathrm{HPC}} \\
(\mathrm{kg} / \mathrm{s})\end{array}$ & $\begin{array}{c}w_{\mathrm{TUR}} \\
(\mathrm{kg} / \mathrm{s})\end{array}$ \\
\hline $\begin{array}{l}\text { Design } \\
\text { condition }\end{array}$ & & 603.0 & 767.6 & 2.26 & 4.7 & 4.7 \\
Opening A & 0.00228 & 583.0 & 693.5 & 1.779 & 6.070 & 4.176 \\
Opening B & 0.00235 & 649.7 & 842.9 & 1.776 & 6.688 & 4.559 \\
Opening C & 0.00288 & 583.6 & 838.3 & 1.784 & 6.080 & 4.188 \\
Opening D & 0.00281 & 569.4 & 755.1 & 1.783 & 5.929 & 4.102 \\
Opening E & 0.00221 & 653.0 & 845.2 & 1.764 & 6.589 & 4.578 \\
Opening F & 0.00217 & 613.0 & 853.5 & 1.715 & 5.749 & 4.299 \\
\hline
\end{tabular}

and positions of nozzles and openings should be carefully designed on pressure vessel.

As a consequence, the scope has been narrowed down to 6 valves A F in Figure 1. And there are several criteria to evaluate the control effects of a bypass valve:

(1) The gas temperature at reactor inlet should not exceed material limit $(623 \mathrm{~K})$.

(2) Temperature variation throughout the recuperator metal core should be minimized to prevent creepfatigue failure.

(3) The smaller is valve flow coefficient, the better is control effect. Because it is proportional to the valve/pipe cross-sectional area through the primary pressure boundary, which would influence the PCU pressure vessel integrity.

In order to compare the control effects of every bypass valves under unified standard, valves of the same model were chosen at each candidate position. In addition, the openings of the valves were tuned to keep the system at 0 power output in the process of numerical simulations (listed in column 2 of Table 2). The scenario for system dynamic response analysis is as follows: the bypass valve opens at $10 \mathrm{~s}$ and reaches its tuned opening instantly, the control rod remains fixed and the shaft rotating speed also remains constant as HTR-10GT employs synchronous generator, and the shaft speed is stabilized by excitation system.

As shown in Figure 6, these 6 valves have different thermal effects at reactor inlet and recuperator low-pressure side inlet. Within the first few seconds, there is a transient due to the thermal inertia of the plate at recuperator core. The opening of A, B, and $\mathrm{E}$ will cause instant decrease of the mass flowrate through high-pressure side and the fluid will be heated more fully with the residual heat in the core; thus $T_{3}$ has an initial increase. The openings of $\mathrm{C}, \mathrm{D}$, and $\mathrm{F}$ lead to the opposite trends.

The long term variation of $T_{3}$ depends basically on the mass flowrate change around the recuperator. Valve $B$ and valve $\mathrm{E}$ would decrease the mass flowrates on both sides of the recuperator which would increase significantly the recuperative effectiveness in HTR-10GT design. Since the reactor inlet temperature in these two cases exceeds the 
TABLE 3: Steady-state features opening dual bypass valves to 0 power output.

\begin{tabular}{lccccc}
\hline Pairs & Former & $\begin{array}{c}A_{v} \text { required }\left(\mathrm{m}^{2}\right) \\
\text { Latter }\end{array}$ & Total & $T_{3}(\mathrm{~K})$ & $\begin{array}{c}T_{3} \text { extremums } \\
(\mathrm{K})\end{array}$ \\
\hline A and B & 0.00095 & 0.00136 & 0.00231 & 617.9 & $631.1 / 603.0$ \\
A and C & 0.00092 & 0.00171 & 0.00263 & 581.9 & $611.7 / 581.9$ \\
A and E & 0.00097 & 0.00128 & 0.00225 & 619.0 & $629.6 / 603.0$ \\
A and F & 0.00103 & 0.00117 & 0.00221 & 597.5 & $613.6 / 596.8$ \\
\hline
\end{tabular}

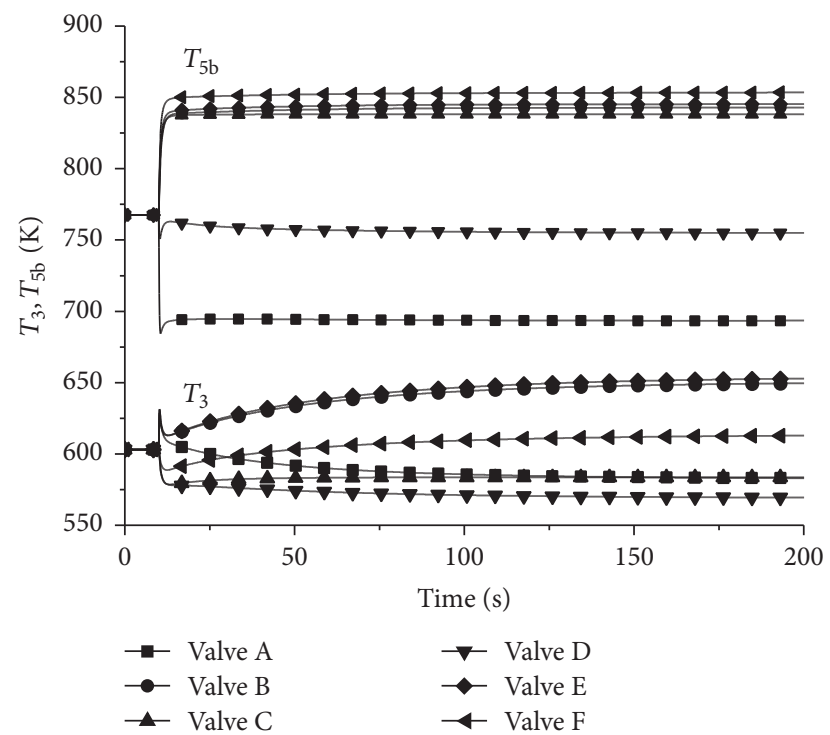

Figure 6: Gas temperature transients at reactor inlet $\left(T_{3}\right)$ and recuperator high-pressure side inlet $\left(T_{5 \mathrm{~b}}\right)$.

material limit, valve $\mathrm{B}$ or valve $\mathrm{E}$ is not allowed to activate without other countermeasures implemented. On the contrary, the opening of valve D increases the mass flowrates on both sides, and the recuperative effectiveness drops and so does $T_{3}$. For valves $\mathrm{A}$ and $\mathrm{C}$, the mass flowrates rise on one side and fall on the other and the recuperative effectiveness also deteriorates but less seriously than when opening valve D. Opening of valve $F$ has the same impact on recuperator as opening C; however, the bypassing of the precooler leads to the temperature rise on $T_{2}$ and eventually increase on $T_{3}$.

As the turbine's expansion ratio decreases, less thermal power was extracted from the working fluid and $T_{5 \mathrm{a}}$ rises significantly. As a result, $T_{5 \mathrm{~b}}$ could be only maintained by mixing cooler gas. That explains why the effect on $T_{5 \mathrm{~b}}$ from valve $\mathrm{A}$ and valve $\mathrm{D}$ differs from the others.

As shown in Figure 7, valve C has relatively low temperature variation throughout the recuperator core plate. Valves B, E, and $\mathrm{F}$ have positive thermal effects (the plate was heated), among them the opening of valves $B$ and $E$ will cause temperature rises as high as around $60 \mathrm{~K}$, whereas valve $A$ and valve $\mathrm{D}$ have negative thermal effects causing temperature decrease about $45 \mathrm{~K}$ and $20 \mathrm{~K}$, respectively.

In conclusion, if only one single bypass valve is employed, valve $B$ and valve $E$ are not on the list, and valve $C$ is a good option for the least thermal shock to the recuperator core and the reactor inlet. However, bypassing through valve $\mathrm{C}$ requires $30 \%$ more cross-sectional area of the opening on the reactor pressure vessel.

4.2. System Responses to Dual Bypass Valves. Based on the system characteristics of single bypass valve, the combination of double bypass valves could be proposed. In order to stabilize $T_{5 \mathrm{~b}}$, valves with opposite effects could work cooperatively for the mutual compensation. As shown in Figure 6, valve D is not suitable for working in pairs because it hardly changes $T_{5 \mathrm{~b}}$; valve A decreasing $T_{5 \mathrm{~b}}$ could work with the rest of 4 valves increasing $T_{5 \mathrm{~b}}$. Therefore, the range of choice for the current study has been narrowed down to 4 dual bypass valve pairs: $\mathrm{A}-\mathrm{B}, \mathrm{A}-\mathrm{C}, \mathrm{A}-\mathrm{E}$, and A-F. In these 4 compositions, the valves were both tuned to achieve long-term 0 power output and 0 temperature variations for $T_{5 \mathrm{~b}}$. Transit behavior of these dual bypass valve schemes was shown in Figure 8 for $T_{3}$ and $T_{5 \mathrm{~b}}$ responses.

It could be achieved by coordination openings of four pair valves to keep $T_{5 \mathrm{~b}}$ unchanged in the long term as shown in Figure 8. However, it was found that transients of around $30 \mathrm{~K}$ temperature drop were inevitable. $T_{3}$ is not key parameter to be precisely controlled. The long-term trends of $T_{3}$ during the transit were listed in Table 3. Temporary overtemperature will happen if valve A works together with valve $\mathrm{B}$ or valve $\mathrm{E}$.

Among all these conditions, the target of reducing power output while maintaining $T_{5 \mathrm{~b}}$ could be achieved. The cooperation of valve $A$ and valve $F$ causes the smallest $T_{3}$ variation and the slightest thermal shock to the recuperator core as shown in Figure 9. Also, the total opening on pressure vessel required by this pair is the minimum.

The advantages of dual bypass valves are quite clear: with the total $A_{v}$ required competitive to the smallest single valve scheme, the coopening of valve $A$ and valve $F$ could reduce thermal shocks at both the reactor inlet and the recuperator core to a great extent. Based on the numerical simulation, the $T_{3}$ variation could be limited within $11 \mathrm{~K}$, and the maximum recuperator core temperature variation could be limited within $5 \mathrm{~K}$.

4.3. Control Effect and Robustness Improvements. As valve A and valve $\mathrm{F}$ were determined as the optimum combination for dual bypass valve control, the critical problem is how to make them work effectively and robustly. The RGA analysis result (see (16)) shows that all values in RGA lie within the interval around 0.5 , which implies the strong coupling between these 2 channels:

$$
\operatorname{RGA}(\mathbf{G})=\left[\begin{array}{ll}
0.4617 & 0.5383 \\
0.5383 & 0.4617
\end{array}\right]
$$



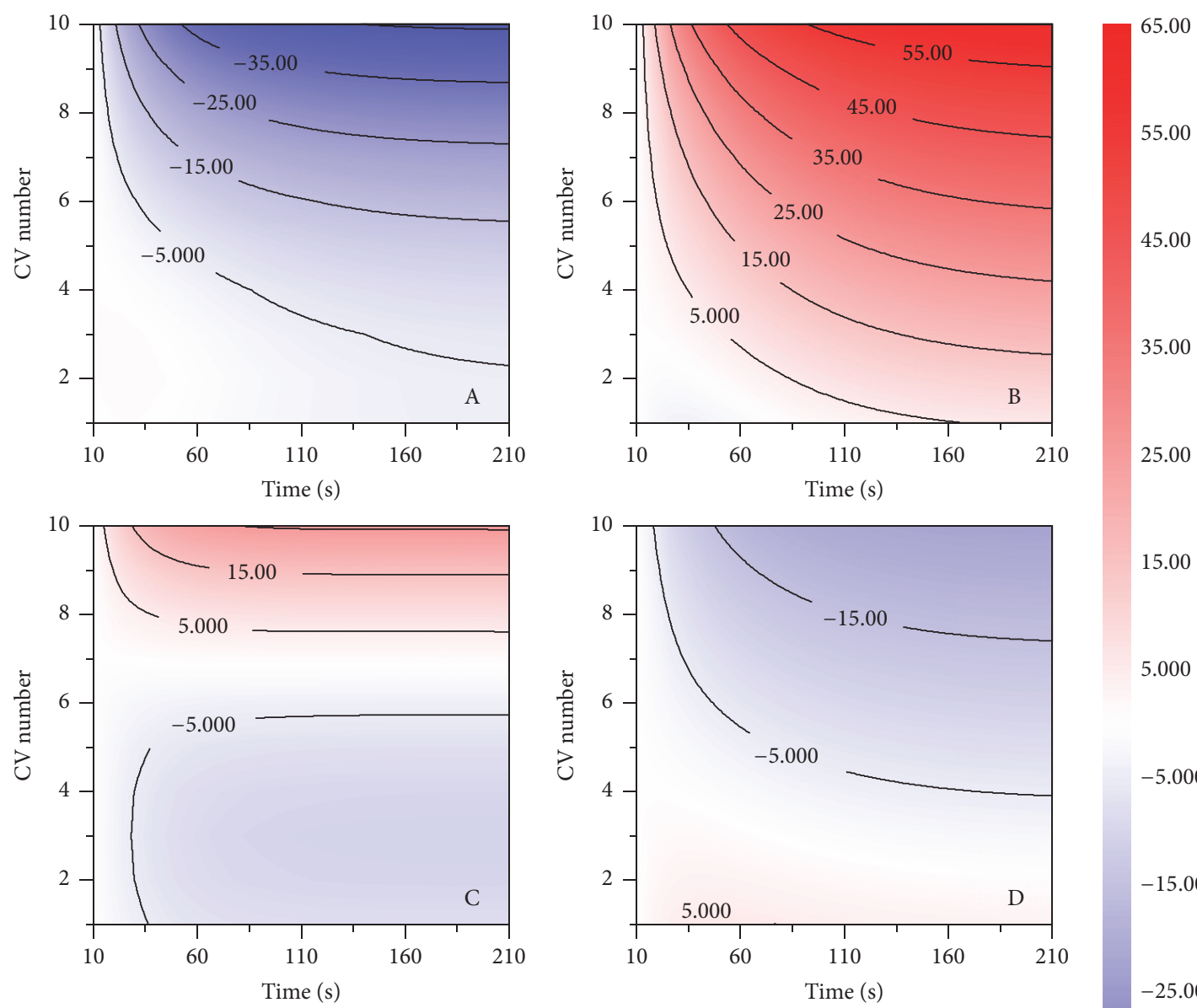

15.00

5.000

$-5.000$

$-15.00$

$-25.00$
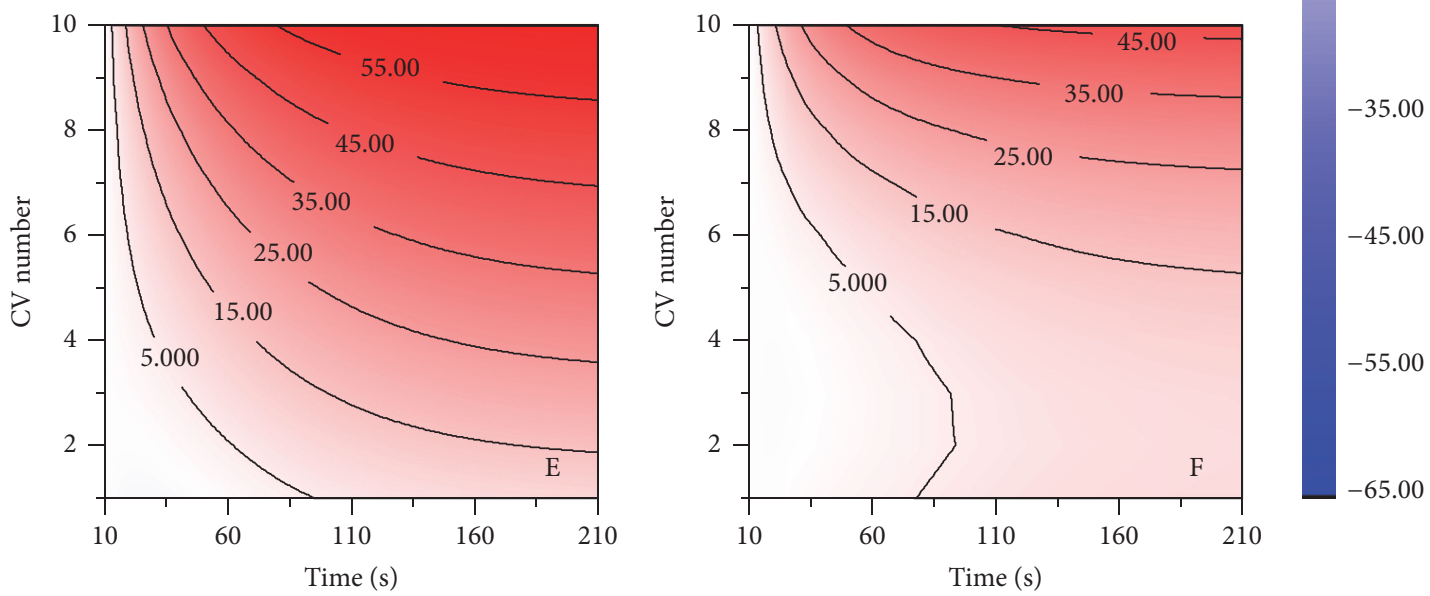

FIGURE 7: Recuperator core temperature responses to single bypass valve.

To eliminate the coupling effect, a controller designed with diagonal matrix method shown in Figure 2 was introduced. The transient responses of power output and temperature are similar regardless of the valve position, as the different effects between opening valve $A$ and valve $F$ were limited within the volume flow rate at inlet and the response of the recuperator, while the other components would not be much influenced.

The same conclusion could be reached with frequency response analysis through Bode diagram shown in Figure 10.
The magnitudes' response fits quite well through the whole frequency range, except the difference for the static gain. The 180-degree phase difference between channel 2-1 and channel 2-2 at very low frequency confirms the opposite effect from valves $\mathrm{A}$ and $\mathrm{F}$ on $T_{5 \mathrm{~b}}$.

Therefore, it is rational to simplify the decoupler to merely gains:

$$
D_{11}=D_{22}=\frac{K_{p 11} K_{p 22}}{K_{p 11} K_{p 22}-K_{p 12} K_{p 21}},
$$




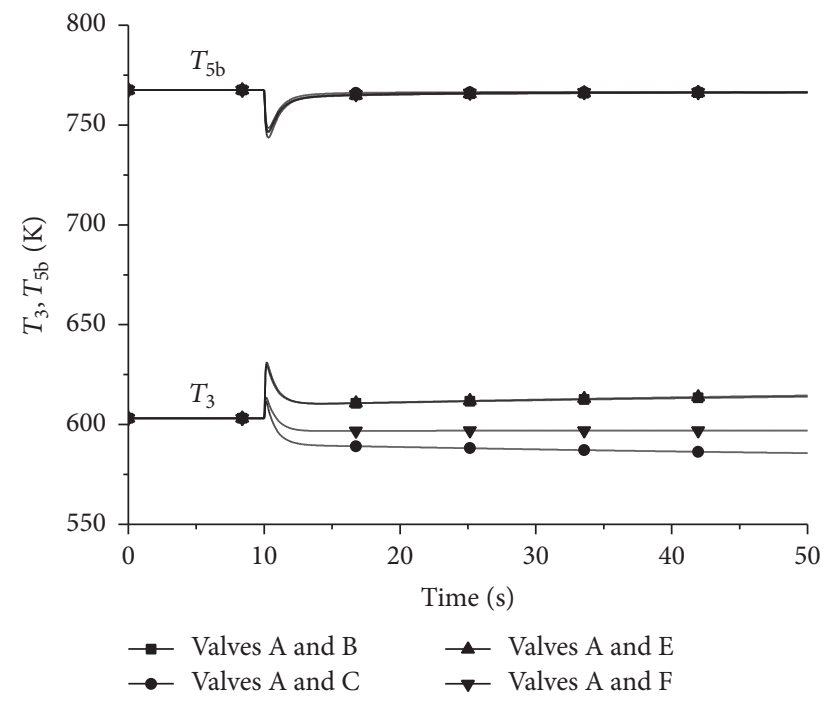

Figure 8: Gas temperature transients at reactor inlet $\left(T_{3}\right)$ and recuperator high-pressure side inlet $\left(T_{5 \mathrm{~b}}\right)$.

$$
\begin{aligned}
& D_{12}=-\frac{K_{p 12} D_{22}}{K_{p 11}}, \\
& D_{21}=-\frac{K_{p 21} D_{11}}{K_{p 22}},
\end{aligned}
$$

where $K$ represents the steady-state gain and the disturbance and error caused by this simplification could be rejected automatically with the integration unit of PID controller.

Figure 11 shows the control effect comparison among single bypass valve control, undecoupled dual bypass valve control, and the decoupled dual bypass valve control. In this scenario, the set point of output power step changed to $30 \%$ of the rated value at $10 \mathrm{~s}$, and then step recovered to $100 \%$ at $60 \mathrm{~s}$. The set point of $T_{5 \mathrm{~b}}$ was fixed at $767.6 \mathrm{~K}$.

When valve $\mathrm{A}$ is working alone, the PID controller designed for SISO with $H_{\infty}$ method had satisfactory control effect: rapid response, accurate tracking for power output, and no overshooting. However, the recuperator low-pressure side inlet temperature was left unconstrained and decreased nearly $60 \mathrm{~K}$ after the opening of valve A. The simultaneous working of the two valves caused overshootings and oscillations in both channels. In the process of the output power recovery, a delay was caused by the regulation on temperature. In contrast, the existing of the decoupler could efficiently reduce the coupling oscillations.

The disk margin (DM) of channel 1 and channel 2 was obtained from the loop-at-a-time stability analysis which allows for simultaneous gain and phase variations. The multiloop disk margin corresponds to allowing simultaneous, independent gain and phase margin variations in each channel. This result guarantees the system's stability including the coupling contribution between 2 loops. By comparing the coupled and decoupled results listed in Table 4, the decoupler could not only enlarge the disk margins compared to the
TABLE 4: Disk margins of the system with 2-way controller.

\begin{tabular}{lcccc}
\hline & \multicolumn{2}{c}{ Gain (dB) } & \multicolumn{2}{c}{ Phase (deg) } \\
& Coupled & Decoupled & Coupled & Decoupled \\
\hline DM channel 1 & 29.2714 & 49.6761 & 86.0608 & 89.6239 \\
DM channel 2 & 12.8434 & 52.1052 & 64.3178 & 89.7156 \\
Multiloop DM & 9.5079 & 38.6080 & 52.9928 & 88.6550 \\
\hline
\end{tabular}

original design but also bring significant improvement on the multiloop disk margin in controller design.

\section{Conclusion}

In this paper, the system's dynamic behaviors after opening single or double bypass valves at all possible positions were clarified through thermal-hydraulics analysis on the integral HTR-10 GT physical model coded with Modelica. The optimum selections for single and double valves were made to maximize the control effect and to minimize the temperature shock. Then control characteristic of the system was obtained through the linear state space representation of the system model. Furthermore, a decoupling controller was designed with diagonal matrix method to reduce the coupling between the 2 control loops. Numerical simulations and disk margin analysis were used to evaluate the effectiveness and the robustness of this newly proposed dual bypass valve control scheme. The main conclusions of the study are as follows:

(1) In one bypass valve control condition, the valve connecting the recuperator high-pressure side outlet and the precooler inlet (valve C in Figure 1) is recommended for the smallest thermal shocks to the reactor inlet and the recuperator core. But larger opening on the primary pressure boundary is required to achieve the same power reduction effect.

(2) Coopening of dual bypass valves with opposite temperature influences can reduce the thermal shocks significantly compared with single bypass valve. It is found that the pair of valve $A$ and valve $F$ is optimal choice with the minimal total valve cross section required.

(3) There are coupling effects between the 2 bypass valve control loops. A decoupler designed with static diagonal matrix method working with 2-way PID controller can effectively reduce the coupling. Meanwhile, the robustness of the system is improved.

\section{Nomenclature}

A: Cross section of flow path, $\mathrm{m}^{2}$

$A_{v}$ : Metric flow coefficient, $\mathrm{m}^{2}$

$c$ : Precursor concentration leading to

delayed neutron source

$F_{k}$ : Specific heats ratio factor

$G_{p}$ : Transfer function of the plant

$h: \quad$ Specific enthalpy, J/kg

$k_{f}$ : Friction coefficient, $\mathrm{m}^{-3}$

$L: \quad$ Length of the flow path, $m$ 

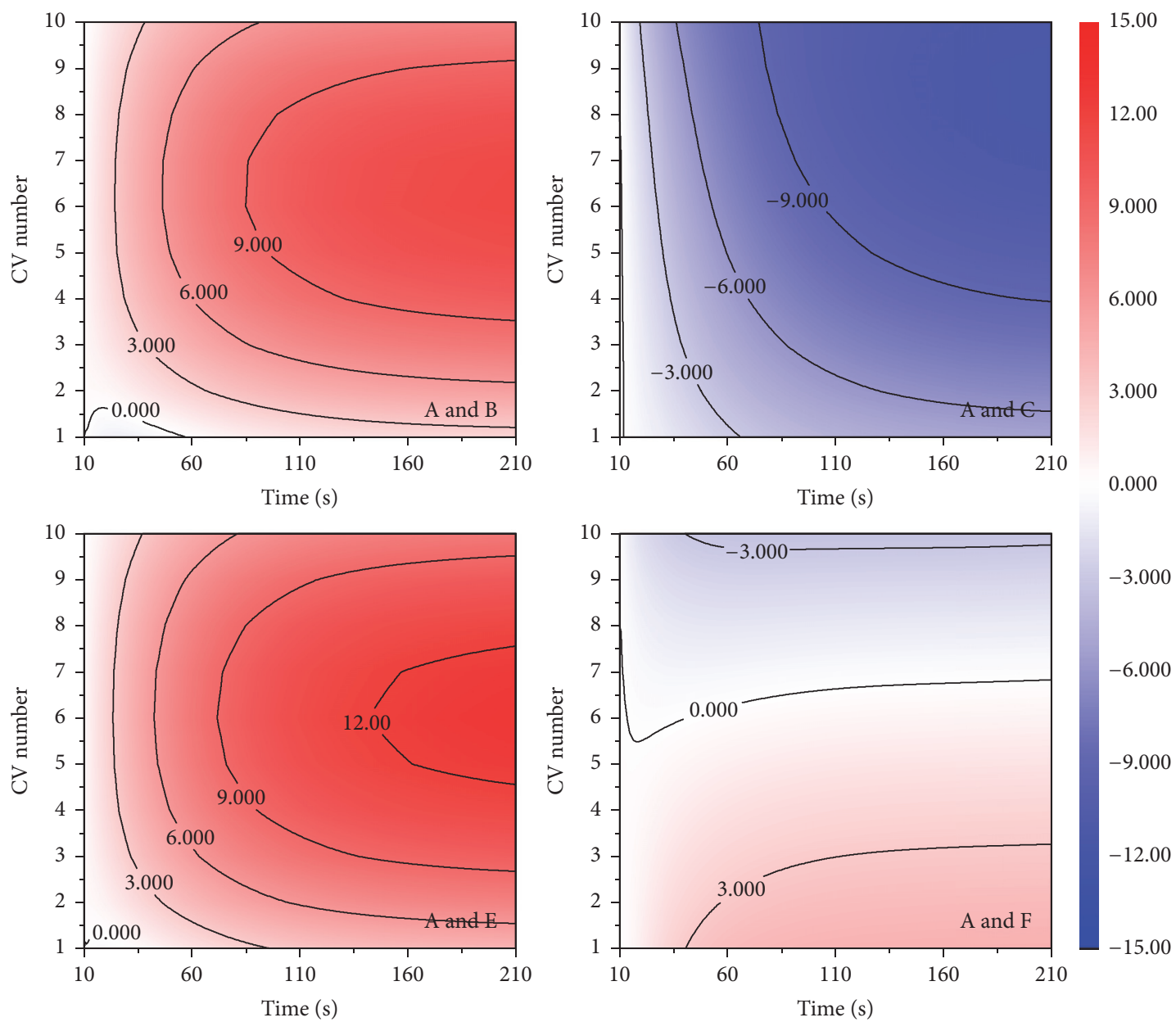

FIGURE 9: Recuperator core temperature responses to dual bypass valves.
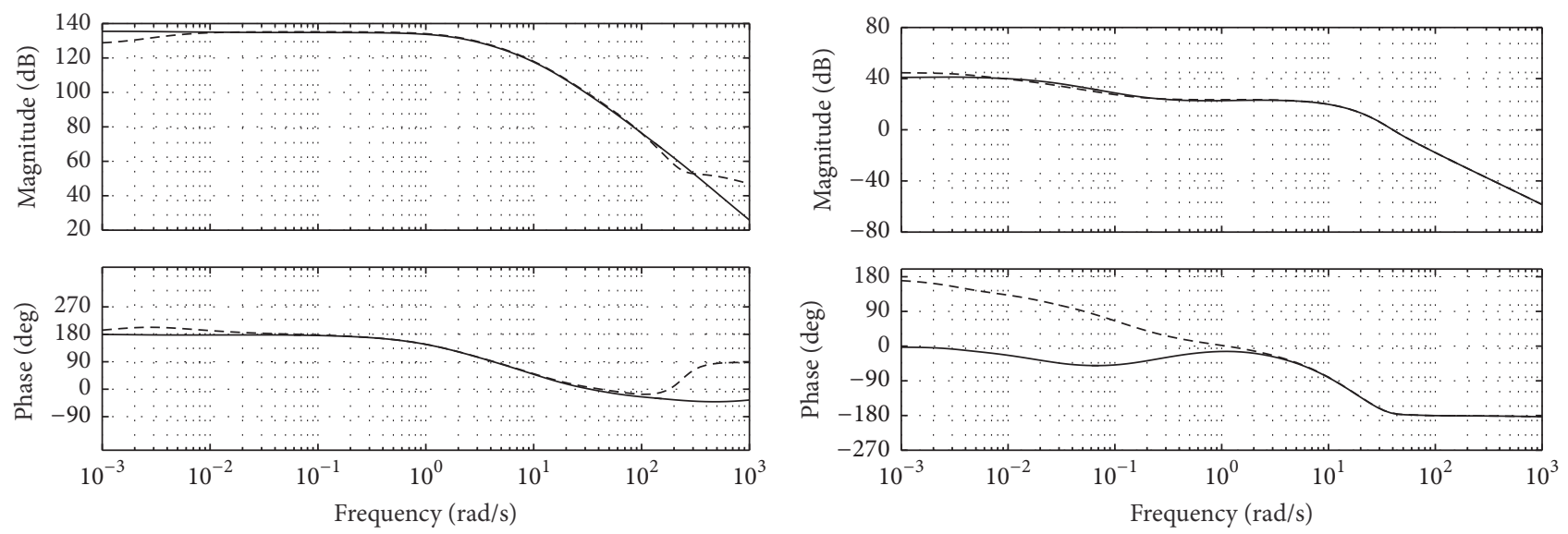

$--G_{p 11}$
$-G_{p 12}$

$--G_{p 21}$
$-G_{p 22}$

(a)

(b)

FIGURE 10: Bode diagram comparison (a) between $G_{p 11}$ and $G_{p 12}$; (b) between $G_{p 21}$ and $G_{p 22}$. 

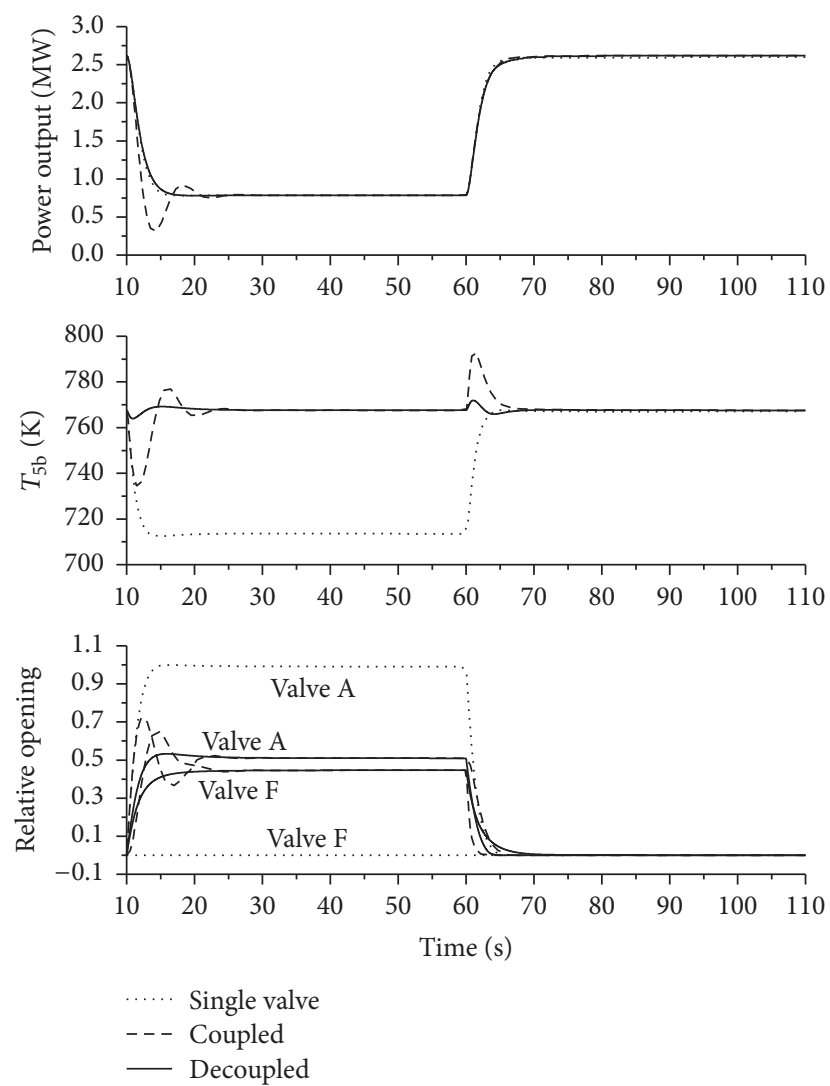

Figure 11: Control effect comparison between single valve, undecoupled controller, and decoupled controller.

$l: \quad$ Length of control volume, $\mathrm{m}$

$\mathrm{N}$ : Total number of control volumes

$N$ : Shaft rotation speed, rpm

$n$ : Neutron population

$p$ : Pressure, $\mathrm{Pa}$

$r:$ Radius on Nyquist plot

$T$ : Temperature, $\mathrm{K}$

$t$ : Time, $s$

$v$ : Specific volume, $\mathrm{m}^{3} / \mathrm{kg}$

$w$ : Mass flowrate, $\mathrm{kg} / \mathrm{s}$

$x$ : Coordinate through flow length and ratio of pressure drop to absolute inlet pressure

$x_{T}$ : Pressure drop ratio factor

$Y$ : Compressibility factor

$\alpha$ : Reactivity temperature coefficient, $\mathrm{K}^{-1}$

$\beta$ : Fraction of the delayed neutrons

$\theta$ : Valve opening and phase

$\Lambda$ : Characteristic period of the mean neutron generation time, $s$

$\lambda$ : Decay constant of the precursors, $\mathrm{s}^{-1}$

$\pi$ : Pressure ratio

$\rho$ : Density of working fluid, $\mathrm{kg} / \mathrm{m}^{3}$

$\rho_{R}$ : Reactivity,

$\bar{\sigma}$ : Maximum singular value

$\varphi$ : Heat flux, $\mathrm{W} / \mathrm{m}^{2}$

$\omega$ : Wetted perimeter, $m$
Subscript

$c$ : Reactor core and corrected value

$d:$ Design value

$f$ : Fuel

$i$ : Group index of delayed neutron precursor

is: Isentropic process

$j:$ Index of control volume

$r$ : Neutron reflector

rod: Reactor control rod

$s$ : Saturated value

Abbreviations

BPV: $\quad$ Bypass valve control

CV: $\quad$ Control volume

DAE: Differential Algebraic Equation

DASSL: Differential/Algebraic System Solver

DGM: Disk gain margin

DM: $\quad$ Disk margin

DPM: $\quad$ Disk phase margin

GTHTR: Gas Turbine High Temperature Reactor

HPC: $\quad$ High-pressure compressor

HTGR: High temperature gas-cooled reactor

IC: Intercooler

INV: Inventory control

LPC: $\quad$ Low-pressure compressor

MGR-GT: Modular high temperature gas-cooled reactor gas turbine power plant

MIMO: Multi-Input Multi-Output

MPBR: Modular pebble bed reactor

PBMR: Pebble bed modular reactor

PC: $\quad$ Precooler

PCU: Power conversion unit

PI: Proportional-Integral

PID: $\quad$ Proportional-Integral-Derivative

RC: $\quad$ Recuperator

REA: Reactor

RGA: Relative Gain Array

ROT: $\quad$ Reactor outlet temperature control

SISO: Single-Input Single-Output

TUR: Turbine.

\section{Competing Interests}

The authors declare that there are no competing interests regarding the publication of this paper.

\section{Acknowledgments}

This work is being supported by National Science and Technology Major Project of the Ministry of Science and Technology of China (Grant no. 2011ZX06901-019) and the National Hi-Tech R\&D Program of China (863 Program) (no. 2005AA511010).

\section{References}

[1] Z. Zuoyi and L. Yong, "Prospects of power conversion technology of direct cycle helium gas turbine for MHTGR," Nuclear Power Engineering, vol. 20, pp. 159-164, 1999. 
[2] C. Wang, Design, Analysis and Optimization of the Power Conversion System for the Modular Pebble Bed Reactor System, Massachusetts Institute of Technology, 2003.

[3] A. Shenoy and R. Potter, "Gas Turbine-Modular Helium Reactor (GT-MHR) conceptual design description report," GA Report 910720, 1996.

[4] H. Sato, X. L. Yan, Y. Tachibana, and Y. Kato, "Load-following operations of VHTR gas-turbine cogeneration system for developing countries," International Journal of Gas Turbine, Propulsion and Power Systems, vol. 4, no. 3, pp. 17-24, 2012.

[5] X. Yan, Dynamic Analysis and Control System Design for an Advanced Nuclear Gas Turbine Power Plant, Massachusetts Institute of Technology, 1990.

[6] J. F. Kikstra and A. H. M. Verkooijen, "Dynamic modeling of a cogenerating nuclear gas turbine plant-part II: dynamic behavior and control," Journal of Engineering for Gas Turbines and Power, vol. 124, no. 3, pp. 734-743, 2002.

[7] P. D. Kemp and C. Nieuwoudt, Operation and Control of the PBMR Demonstration Power Plant, American Society of Mechanical Engineers, 2006.

[8] Z. Huang, J. Wang, and J. Li, "Study on the thermodynamic cycle of HTR-10GT," in Proceedings of the 2nd International Topical Meeting on High Temperature Reactor Technology, Beijing, China, September 2004.

[9] R. Sa, Study on Dynamic Features of Bypass Valve Control for HTGR Brayton Cycle, Tsinghua University, 2007.

[10] A. S. Boksenbom and R. Hood, "General algebraic method applied to control analysis of complex engine types," 1950.

[11] P. Fritzson, P. Aronsson, A. Pop et al., "OpenModelica-a free open-source environment for system modeling, simulation, and teaching," in Proceedings of the Joint IEEE Conference on Control Applications (CCA), Computer-Aided Control Systems Design Symposium (CACSD) and International Symposium on Intelligent Control (ISIC '06), pp. 1588-1595, October 2006.

[12] K. E. Brenan, S. L. Campbell, and L. R. Petzold, Numerical Solution of Initial-Value Problems in Differential-Algebraic Equations, SIAM, 1996.

[13] A. B. Wassell, "Reynolds number effects in axial compressors," Journal of Engineering for Gas Turbines and Power, vol. 90, no. 2, pp. 149-156, 1968.

[14] A. Leyzerovich, Large Power Steam Turbines: Design and Operation, Pennwell Publishing, Tulsa, Okla, USA, 1997.

[15] E. H. Bristol, "On a new measure of interaction for multivariable process control," IEEE Transactions on Automatic Control, vol. 11, no. 1, pp. 133-134, 1966.

[16] D. Bates and I. Postlethwaite, Robust Multivariable Control of Aerospace Systems, IOS Press, 2002. 

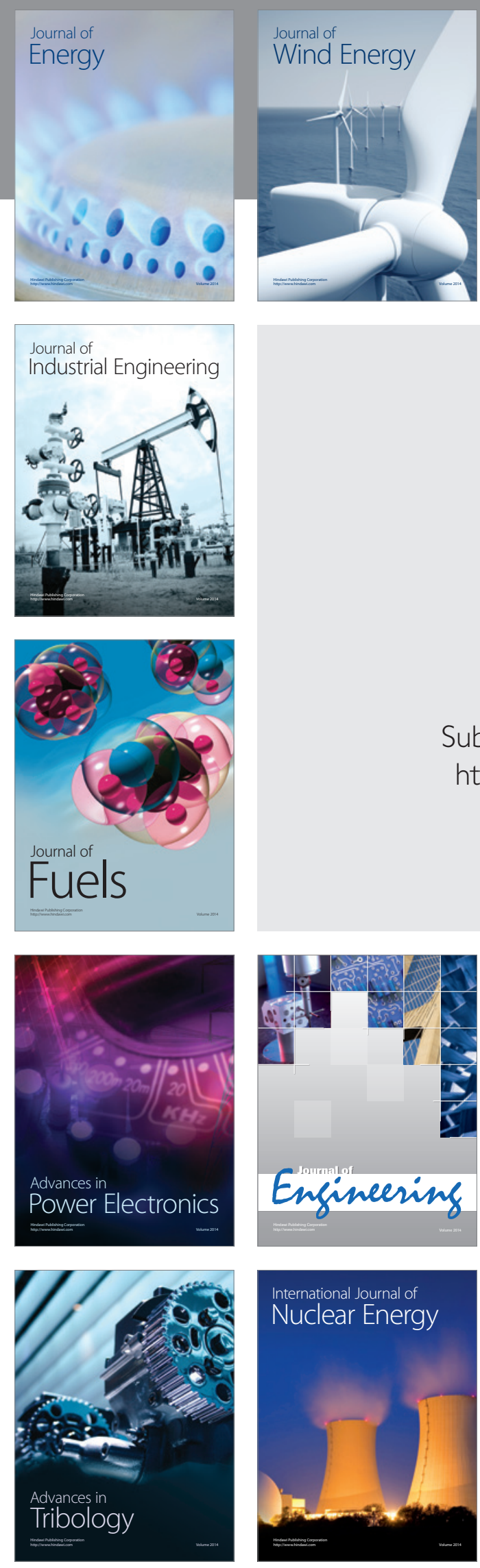

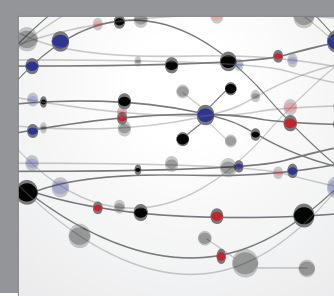

The Scientific World Journal
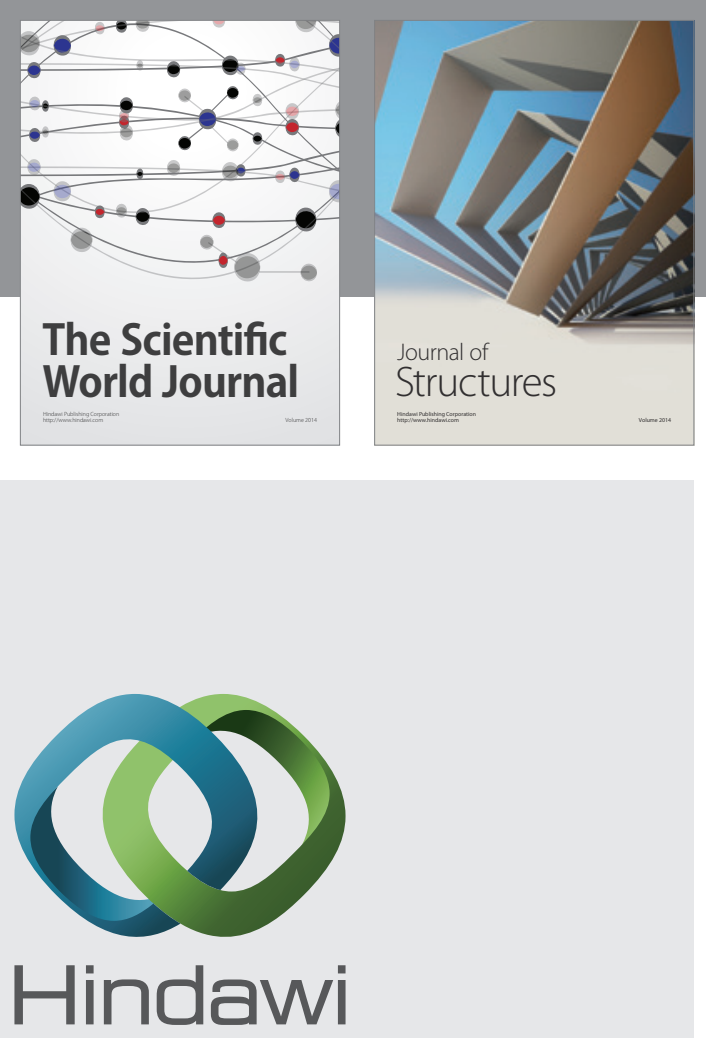

Submit your manuscripts at

https://www.hindawi.com
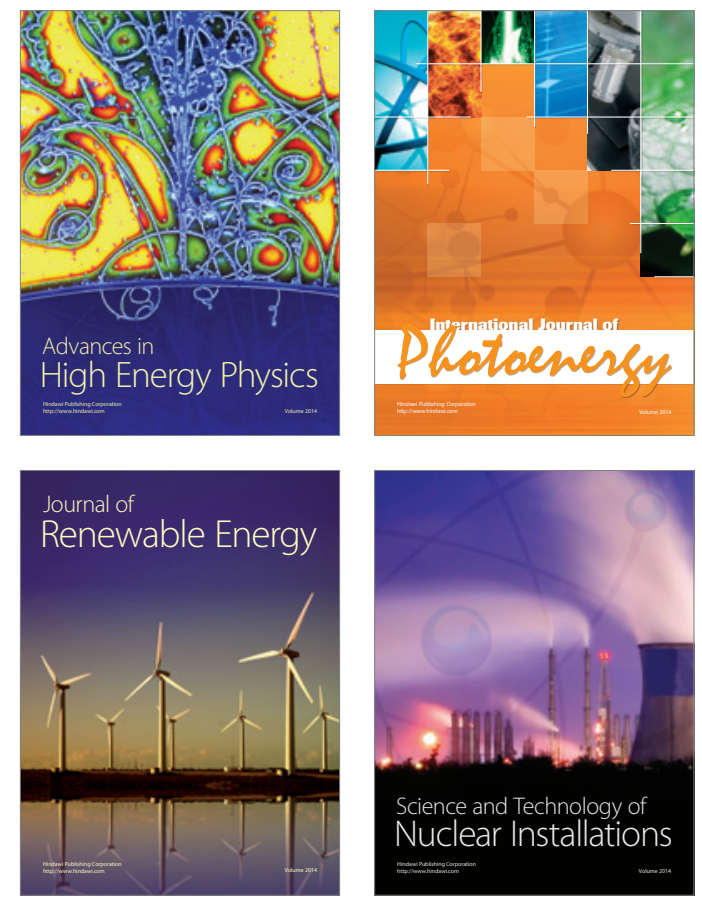
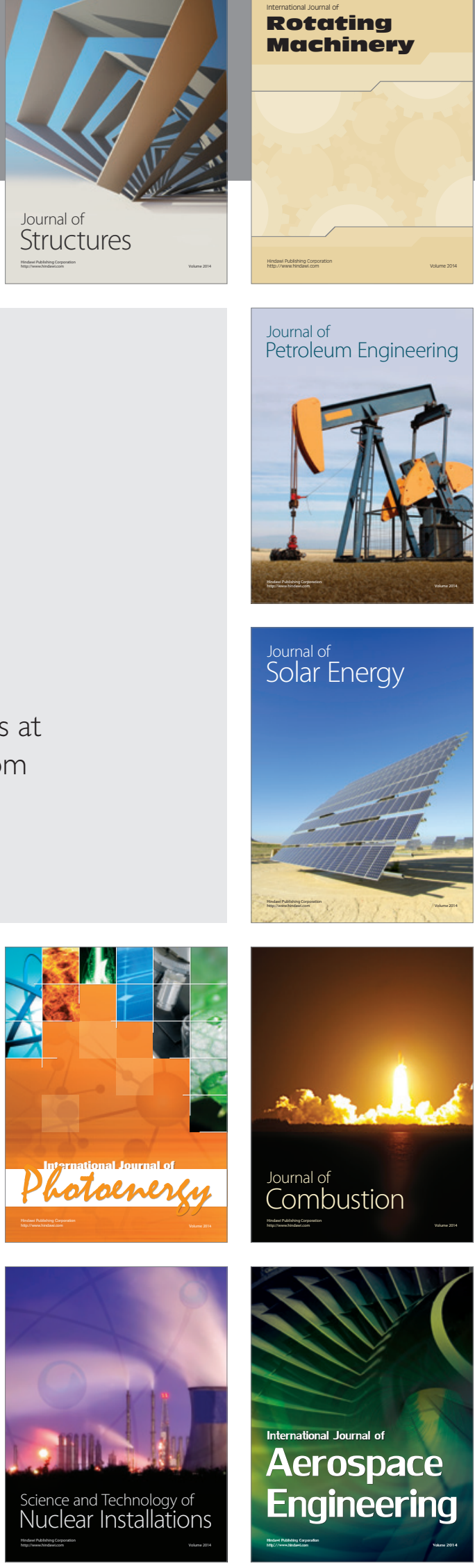